University of South Florida

DIGITAL COMMONS

Digital Commons @ University of

@ UNIVERSITY OF SOUTH FLORIDA

South Florida

Marine Science Faculty Publications

College of Marine Science

$10-2008$

\title{
GRACE Observes Small-scale Mass Loss in Greenland
}

\author{
B. Wouters \\ Delft University of Technology \\ D. Chambers \\ University of Texas, donc@usf.edu \\ E.J. O. Schrama \\ Delft University of Technology
}

Follow this and additional works at: https://digitalcommons.usf.edu/msc_facpub

Part of the Marine Biology Commons

\section{Scholar Commons Citation}

Wouters, B.; Chambers, D.; and Schrama, E.J. O., "GRACE Observes Small-scale Mass Loss in Greenland" (2008). Marine Science Faculty Publications. 195.

https://digitalcommons.usf.edu/msc_facpub/195

This Article is brought to you for free and open access by the College of Marine Science at Digital Commons @ University of South Florida. It has been accepted for inclusion in Marine Science Faculty Publications by an authorized administrator of Digital Commons @ University of South Florida. For more information, please contact digitalcommons@usf.edu. 


\title{
GRACE observes small-scale mass loss in Greenland
}

\author{
B. Wouters, ${ }^{1}$ D. Chambers ${ }^{2}$ and E. J. O. Schrama ${ }^{1}$ \\ Received 28 May 2008; revised 31 August 2008; accepted 8 September 2008; published 16 October 2008.
}

[1] Using satellite gravity data between February 2003 and January 2008, we examine changes in Greenland's mass distribution on a regional scale. During this period, Greenland lost mass at a mean rate of $179 \pm 25 \mathrm{Gt} / \mathrm{yr}$, equivalent to a global mean sea level change of $0.5 \pm$ $0.1 \mathrm{~mm} / \mathrm{yr}$. Rates increase over time, suggesting an acceleration of the mass loss, driven by mass loss during summer. The largest mass losses occurred along the southeastern and northwestern coast in the summers of 2005 and 2007, when the ice sheet lost $279 \mathrm{Gt}$ and $328 \mathrm{Gt}$ of ice respectively within 2 months. In 2007, a strong mass loss is observed during summer at elevations above $2000 \mathrm{~m}$, for the first time since the start of the observations. Citation: Wouters, B., D. Chambers, and E. J. O. Schrama (2008), GRACE observes small-scale mass loss in Greenland, Geophys. Res. Lett., 35, L20501, doi:10.1029/2008GL034816.

\section{Introduction}

[2] Several studies have addressed changes in the behavior of the Greenland ice sheet over the last few years. Many of the outlet glaciers have increased their speed [Stearns and Hamilton, 2007; Rignot and Kanagaratnam, 2006; Dietrich et al., 2007; Luckman et al., 2006] and strong thinning of the ice sheet has been observed along the coast [Thomas et al., 2006; Zwally et al., 2005]. Summer temperature increased by $1.7^{\circ} \mathrm{C}$ between 1991 and 2006 , with 2003, 2005 and 2007 having the highest summer temperature in 61 years [Hanna et al., 2008b].

[3] The Gravity Recovery and Climate Experiment (GRACE) satellites have been providing the scientific community with a quasi-continuous record of the Earth's gravity field over the last 5 years. Due to its global coverage, it offers an excellent tool to study mass changes over large areas. Assuming the majority of the change is related to water mass transport [Wahr et al., 1998], several authors have used GRACE data to estimate the rate of mass loss over Greenland. Due to the limited spatial resolution and the presence of non-random noise, obtaining mass estimates from GRACE data is not straightforward and results vary widely between $101 \mathrm{Gt} / \mathrm{yr}$ and $227 \mathrm{Gt} / \mathrm{y}$ [Luthcke et al., 2006; Ramillien et al., 2006; Velicogna and Wahr, 2006; Chen et al., 2006]. The large differences in the estimates can partly be attributed to the different observation periods used in these studies combined with the large variability in Greenland's mass balance, but are

\footnotetext{
${ }^{1}$ Delft Institute of Earth Observation and Space Systems, Delft University of Technology, Delft, Netherlands.

${ }^{2}$ Center for Space Research, University of Texas at Austin, Austin, Texas, USA.
}

Copyright 2008 by the American Geophysical Union. 0094-8276/08/2008GL034816 mainly due to the different methods used. Besides differences introduced by the different groups processing the raw data, differences can be caused by truncating coefficients differently, using area smoothing functions or averaging gridded and smoothed data, and from failing to restore power lost by smoothing. Here, we present results based on 58 monthly GRACE observations (CSR RL04) between February 2003 to January 2008.

\section{Method}

[4] The CSR RL04 GRACE solutions are provided in terms of Stokes coefficients and are known to be contaminated by noise at the shorter wavelengths. We apply a filtering technique based on empirical orthogonal function (EOF) decomposition of the spherical harmonics grouped by order. The obtained principal components (PC) are tested for temporal random behavior and the series of coefficients are then rebuild using the non-random PCs and associated EOFs, see Wouters and Schrama [2007] for details. Also, the $C_{20}$ terms were replaced by values based on satellite laser ranging data (J. Ries, personal communication, 2008). After filtering, the coefficients are converted to maps of equivalent water height. To suppress any remaining noise in the maps of monthly mass anomalies, we convolve the solutions with a Gaussian smoothing kernel with a $250 \mathrm{~km}$ halfwidth radius. A trend as well as an annual and semimanual varying signal is estimated through a least squares fit to the monthly observations (Figure 1).

[5] Smoothing the GRACE maps will inevitably lead to attenuation of the original signal. Additionally, contamination from external signals, such as changes in the continental hydrology or ocean bottom pressure in the regions surrounding Greenland, will occur. Velicogna and Wahr [2006] estimated a scaling factor to compensate for signal attenuation caused by smoothing and truncation of the spherical harmonics and removed the effect of external mass changes by means of geophysical models. However, this method was used to obtain temporal mass variations over the whole ice sheets or large portions, i.e. the North and South part, only. In this report we take a different approach, based on forward modeling of higher resolution mass variations that agree with the GRACE observations once smoothed. Similar methods have been used before, based on either spherical harmonics [Chen et al., 2006] or using direct ranging measurements between the GRACE satellites [Luthcke et al., 2006], however, in contrast to Chen et al. [2006], we do not limit our study to the regions of largest losses, but estimate mass changes over the entire ice sheet. To do so, we divide the ice covered area into 8 different zones corresponding to the major glacier drainage systems, based on satellite radar and airborne laser altimetry observations [Zwally et al., 2005]. Furthermore, we partition each of the basins in two zones, located above 

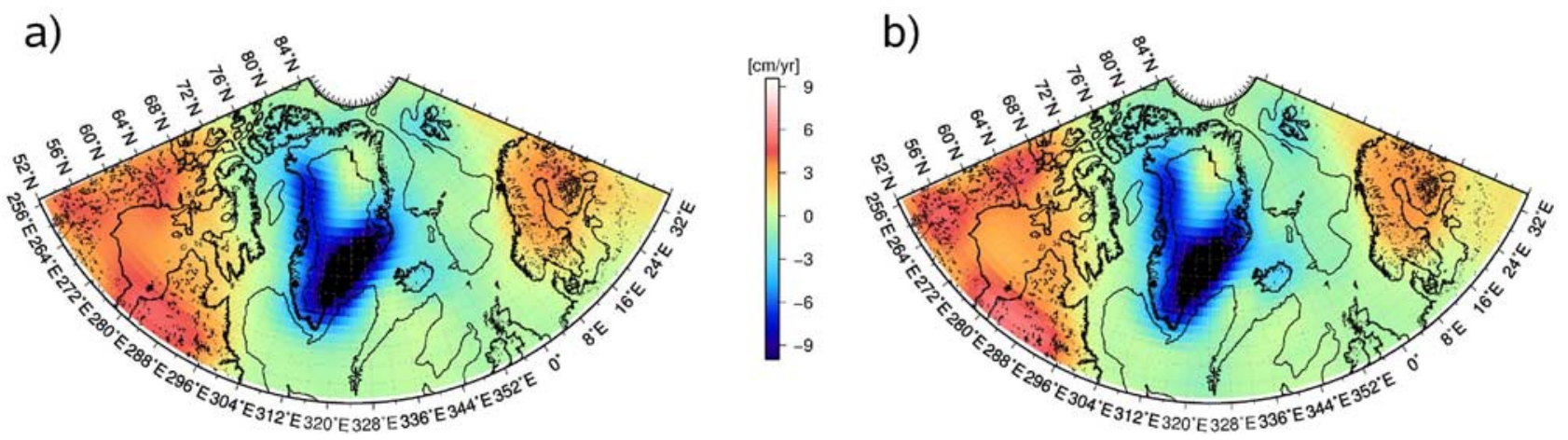

Figure 1. Changes in equivalent water height over Greenland between February 2003 and January 2008 as (a) observed by GRACE and (b) simulated with the forward model, both smoothed with a $250 \mathrm{~km}$ Gaussian filter. A maximum negative value of $12.5 \mathrm{~cm} / \mathrm{yr}$ is found at $\left(39.5^{\circ} \mathrm{W}, 66.5^{\circ} \mathrm{N}\right)$, close to the Helheim glacier. Elevation contours are plotted at $2000 \mathrm{~m}$ intervals. Black color is off-scale.

and below the $2000 \mathrm{~m}$ elevation contour respectively (Figure S1 of the auxiliary material). ${ }^{1}$ Each of the 16 basins is then assigned a preliminary estimated mass change rate, based on Rignot and Kanagaratnam [2006]. The same procedure is repeated for the regions surrounding Greenland, where we take relatively large basins over the oceans, since the expected signals are small here. An iterative procedure is then started, in which the model of surface mass change is converted to Stokes coefficients up to degree 60 , of which the degree $l=1$ term (which is not observed by GRACE) is removed and the Gaussian smoothing kernel is applied. The forward model is compared with the GRACE trend map and the mass change rates in each of the basins are adjusted, after which the procedure is re-initialized. This repeated until optimal agreement with the GRACE observations is reached (i.e., minimal spatial rms of the differenced maps). The mass variations in each 58 monthly solution are estimated using a similar methodology.

\section{Results}

[6] After convolving with the $250 \mathrm{~km}$ Gaussian smoothing kernel, excellent agreement is obtained between the forward model and GRACE (Figure 1): integrated over the entire ice sheet, the absolute differences between the observed and modeled mass rates sum up to $8 \mathrm{Gt} / \mathrm{yr}$ (after smoothing), with values for the individual basins in the order of $0.5 \mathrm{Gt} / \mathrm{yr}$. The unsmoothed forward model provides an average water height change for each basin (Figure 2 and Table 1), which can be multiplied by the basin's area and the density of water to obtain an estimate of the total mass change in the basin. By summing the results for all basins, we find a total mass loss over Greenland (continental ice only, $1.768 \times 10^{6} \mathrm{~km}^{2}$ in total) of $171 \pm 13 \mathrm{Gt} / \mathrm{yr}$ for the period of February 2003 to January 2008. The error bars are obtained by quadratically summing (1) the absolute difference between our forward model and the GRACE observations, integrated over the basin, (2) the calibrated errors in the GRACE Stokes coefficients (10 Gt/yr), (3) an estimate

\footnotetext{
${ }^{1}$ Auxiliary materials are available in the HTML. doi:10.1029/ 2008 GL034816.
}

of tidal errors ( $2 \mathrm{Gt} / \mathrm{yr})$ and (4) a correction for the influence of the filter ( $2 \mathrm{Gt} / \mathrm{yr}$ ) (see auxiliary material).

[7] Part of the signal observed by GRACE is due to solid earth movement in response to changes in the surface load since the last glacial maximum (LGM), known as postglacial rebound (PGR). We correct our GRACE derived maps of mass changes using the PGR model from Paulson et al. [2007], based on the ICE-5G ice load history and a solid Earth model adjusted to match GRACE observations over Fennoscandia and the Hudson Bay. As a measure for the PGR correction error we use the value of Velicogna and Wahr [2006], who used a range of viscosity profiles and different deglaciation history models over Greenland and found the PGR correction to vary by $\pm 21 \mathrm{Gt} / \mathrm{yr}$ over Greenland. Correcting for the effects of PGR adds an additional $-8 \mathrm{Gt} / \mathrm{yr}$ to the estimated trend, resulting in a mean trend of $-179 \pm 24 \mathrm{Gt} / \mathrm{yr}$ between February 2003 to January 2008. We note that recent results [e.g., Ivins and Wolf, 2008, and references therein) suggest that the PGR error might be underestimated and the uncertainty is still under debate. Further investigation of this issue is crucial to come to smaller and more reliable error bars on the GRACE based mass change estimates over Greenland.

[8] Trends based on previous releases of different GRACE processing center have been known to show little agreement. To test the robustness of our estimates, we estimated a trend based on the GFZ RL04 solutions. Over a similar period, excluding the period of June - September 2004 when the GRACE satellites were in a near-repeat orbit resulting in degraded quality of GFZ the solutions, we find a trend of $-173 \pm 28 \mathrm{Gt} / \mathrm{yr}$, which is well within the error bounds of our trend based on the CSR data.

[9] Our mass change estimates over Greenland are considerably larger than those in some earlier studies, which reported a trend of $-129 \pm 15 \mathrm{Gt} / \mathrm{yr}$ (July 2002 to March 2005) [Ramillien et al., 2006] and -101 \pm 16 Gt/yr (July 2003 to July 2005) [Luthcke et al., 2006]. Over an identical period as the latter, we find a comparable trend of $-121 \pm$ $27 \mathrm{Gt} / \mathrm{yr}$, consistent within the range of error. The pattern of mass change matches well, with thinning along the coast and a slight growth in the inland regions observed in both studies. Between January 2006 to January 2008, we find a trend of $-204 \pm 25 \mathrm{Gt} / \mathrm{yr}$, which implies that the larger mass 
a)

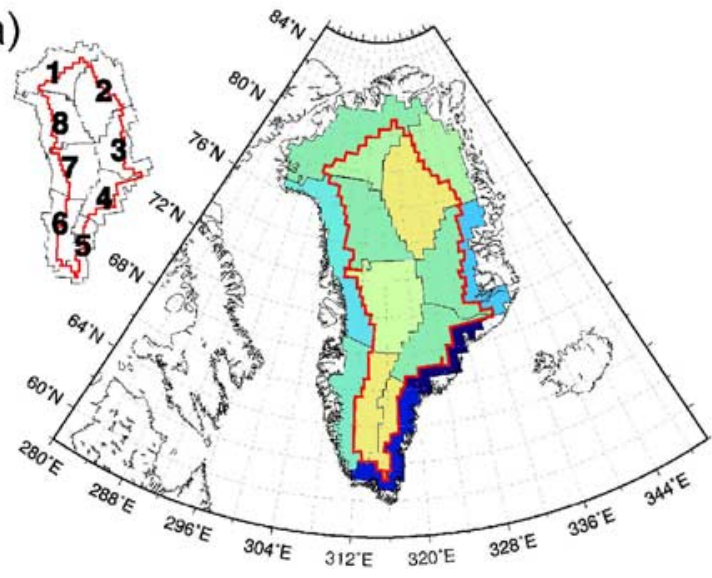

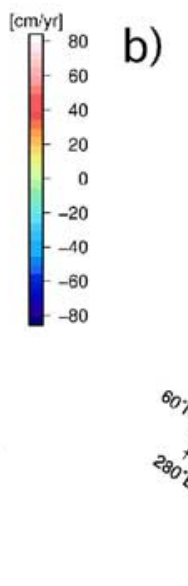

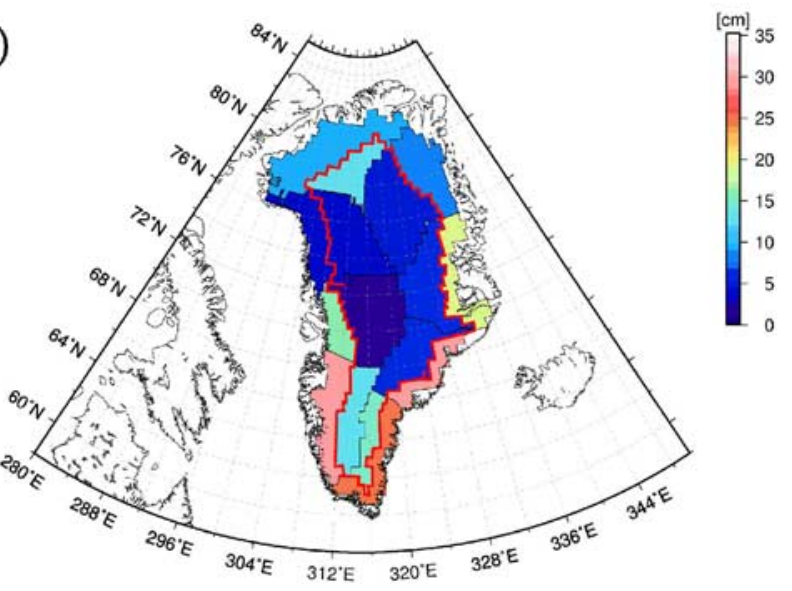

Figure 2. (a) Trends for 2003-2007 and (b) amplitude of annual signal estimated with the forward model. The inlay in the upper left corner shows the basin numbers used throughout the text. The bold red line delimitates the approximate $2000 \mathrm{~m}$ elevation contour. Trends have been corrected for post glacial rebound effects.

loss rate over the entire period $(-179 \pm 19 \mathrm{Gt})$ is due to a change in the behavior of the Greenland ice sheet rather than to the different method and data used. On the other hand, our estimate for $2003-2005$ is notably smaller than the trends of Velicogna and Wahr [2006] and Chen et al. [2006], which are in the order of $230 \mathrm{Gt} / \mathrm{yr}$ between mid 2002 and the end 2005. These studies used a different method and relied on an older GRACE data release, with larger associated errors and a lower spatial resolution. Moreover, the estimate of Chen et al. [2006] may have been biased by the fact that only regions showing large mass losses were modeled, which ignored that some areas have gained mass or are in balance.

[10] As in previous studies [Ramillien et al., 2006; Velicogna and Wahr, 2006; Chen et al., 2006], our approach is based on global Stokes coefficients, but allows one to allocate the changes in mass to specific basins. The mass losses are mainly taking place in the regions situated below $2000 \mathrm{~m}$, where we find a negative trend of $186 \pm 19 \mathrm{Gt} / \mathrm{yr}$ (Figure 2 and Table 1). Most pronounced trends are found in the coastal zones ranging from the east to the southeast (basins 4 and 5), which agrees well with the observed thinning of the Kangerdlugssuaq and Helheim Glacier between 2001 and 2006 [Stearns and Hamilton, 2007; Luckman et al., 2006]. We also observe widespread mass loss in the northwestern coastal zones (basins 7 and 8), which confirms the findings of Rignot and Kanagaratnam [2006] and Thomas et al. [2006], based on InSAR and laser altimetry respectively. The interior of Greenland (>2000 m) shows an insignificant positive trend of $7 \pm 18 \mathrm{Gt} / \mathrm{yr}$ and appears to be in balance. Small positive rates are found in the northern basin 2 and the southern basins 5 and 6 . Positive elevation changes in Greenland's interior have been observed using satellite radar [e.g., Zwally et al., 2005] and laser altimetry [Thomas et al., 2006], particularly in the South of Greenland (corresponding to basins 5 and 6), but such altimeter measurement are greatly affected by uncertainties in the density profile of the ice, driven by variability in accumulation and temperature.

[11] A pronounced seasonal signal (Figure 2) is found in the southern coastal zones (basins 4-6), with a maximum of
$30 \pm 4 \mathrm{Gt}$ in basin 6 . In contrast, the regions at higher elevations show little or no annual signal (total mass amplitude of $12 \pm 11 \mathrm{Gt}$ ). The overall annual amplitude for the Greenland ice sheet is $98 \pm 18 \mathrm{Gt}$, reaching its maximum on day $116 \pm 13$.

[12] Figure 3 shows the temporal evolution Greenland's mass balance, for the entire ice sheet, as well as for the regions situated below and above $2000 \mathrm{~m}$ separately. Mass

Table 1. Overview of the Trends and Annual Amplitude Observed in the Individual Basins Between February 2003 and January $2008^{\mathrm{a}}$

\begin{tabular}{|c|c|c|c|c|c|}
\hline & $\begin{array}{c}\text { Basin } \\
\text { Area } \\
\left(10^{3} \mathrm{~km}^{2}\right)\end{array}$ & $\begin{array}{l}\text { Trend } \\
(\mathrm{Gt} / \mathrm{yr})\end{array}$ & $\begin{array}{l}\text { Average } \\
\text { Trend } \\
(\mathrm{cm} / \mathrm{yr})\end{array}$ & $\begin{array}{c}\text { Amplitude } \\
\text { (Gt) }\end{array}$ & $\begin{array}{l}\text { Phase } \\
\text { (Day) }\end{array}$ \\
\hline \multicolumn{6}{|c|}{ Greenland $<2000 m$} \\
\hline Basin 1 & 177 & $-12 \pm 4$ & $-6.8 \pm 2$ & $17 \pm 3$ & $69 \pm 24$ \\
\hline Basin 2 & 112 & $-6 \pm 4$ & $-5.4 \pm 4$ & $10 \pm 3$ & $123 \pm 38$ \\
\hline Basin 3 & 84 & $-25 \pm 5$ & $-30 \pm 6$ & $16 \pm 5$ & $130 \pm 37$ \\
\hline Basin 4 & 58 & $-49 \pm 4$ & $-85 \pm 7$ & $17 \pm 4$ & $103 \pm 21$ \\
\hline Basin 5 & 80 & $-51 \pm 5$ & $-64 \pm 7$ & $20 \pm 5$ & $137 \pm 36$ \\
\hline Basin 6 & 104 & $-13 \pm 5$ & $-13 \pm 5$ & $30 \pm 4$ & $123 \pm 20$ \\
\hline Basin 7 & 55 & $-14 \pm 3$ & $-25 \pm 6$ & $9 \pm 3$ & $117 \pm 37$ \\
\hline Basin 8 & 93 & $-16 \pm 4$ & $-17 \pm 5$ & $3 \pm 4$ & $254 \pm 259$ \\
\hline Total & 763 & $-186 \pm 19$ & $-24 \pm 2$ & $109 \pm 15$ & $118 \pm 12$ \\
\hline \multicolumn{6}{|c|}{ Greenland $>2000 m$} \\
\hline Basin 1 & 81 & $-1 \pm 4$ & $-1.2 \pm 5$ & $10 \pm 4$ & $230 \pm 88$ \\
\hline Basin 2 & 197 & $19 \pm 6$ & $9.6 \pm 3$ & $10 \pm 5$ & $322 \pm 181$ \\
\hline Basin 3 & 136 & $-10 \pm 5$ & $-7.3 \pm 3$ & $9 \pm 4$ & $48 \pm 50$ \\
\hline Basin 4 & 111 & $-7 \pm 3$ & $-6.3 \pm 3$ & $6 \pm 3$ & $119 \pm 41$ \\
\hline Basin 5 & 55 & $6 \pm 6$ & $11 \pm 11$ & $8 \pm 6$ & $31 \pm 79$ \\
\hline Basin 6 & 94 & $11 \pm 5$ & $12 \pm 5$ & $12 \pm 4$ & $281 \pm 66$ \\
\hline Basin 7 & 179 & $2 \pm 5$ & $1.1 \pm 3$ & $4 \pm 4$ & $266 \pm 258$ \\
\hline Basin 8 & 152 & $-13 \pm 5$ & $-8.6 \pm 3$ & $6 \pm 5$ & $115 \pm 48$ \\
\hline Total & 1005 & $7 \pm 18$ & $0.7 \pm 2$ & $12 \pm 11$ & $326 \pm 176$ \\
\hline \multicolumn{6}{|c|}{ Non-Greenland } \\
\hline Svalbard & 179 & $-8.8 \pm 3$ & $-4.9 \pm 1$ & $9.9 \pm 3$ & $160 \pm 50$ \\
\hline Iceland & 181 & $-11.4 \pm 3$ & $-6.3 \pm 1$ & $8.9 \pm 3$ & $102 \pm 28$ \\
\hline Ellesmere Is1 & 428 & $-15.8 \pm 9$ & $-4 \pm 2$ & $6.9 \pm 6$ & $192 \pm 50$ \\
\hline
\end{tabular}

${ }^{\text {a }}$ Statistics are given for regions below and above $2000 \mathrm{~m}$ in Greenland as well as some selected surrounding regions. Average trend is obtained by dividing the basins total value by its area and density of water. 

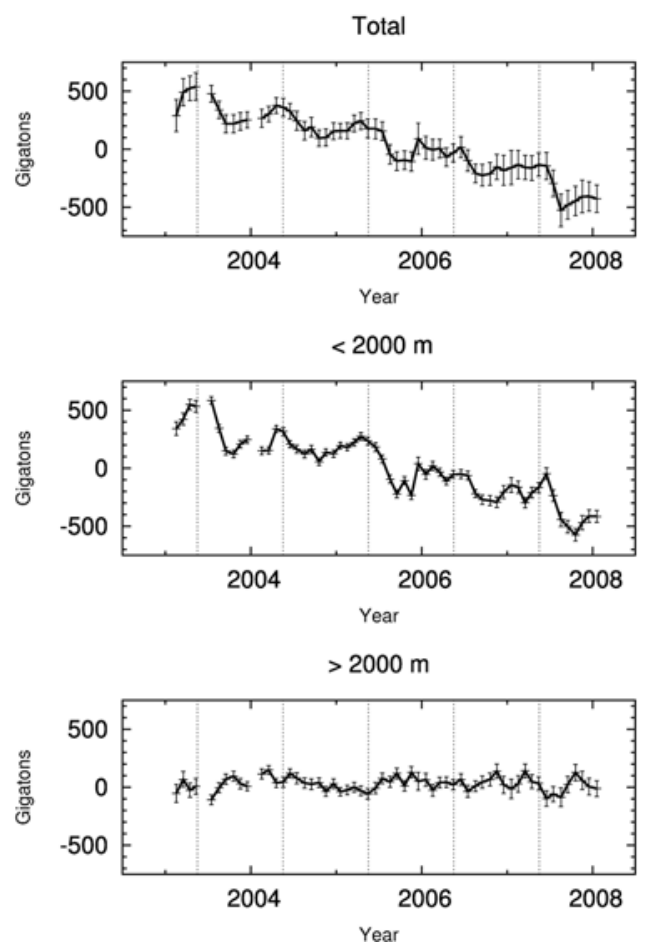

Figure 3. Time series of the monthly GRACE solutions between February 2003 and January 2008, for (top) the entire Greenland ice sheet, (middle) the regions below $2000 \mathrm{~m}$ and (bottom) the regions above $2000 \mathrm{~m}$. Error bars are based on the calibrated GRACE errors and the misfit between the forward model and the GRACE observation, integrated over the region of interest. The vertical dashes indicate the middle of month May for each year, roughly coinciding with the start of the summer seasons.

builds up slowly between October and April, followed by rapid loss of mass between May and September. The amplitude of the summer ice loss varies between the years, with a maximum in 2007, in which 338 Gt was lost in summer (Table 2, calculated as the difference between the April-May-June and August-September-October mean mass over Greenland, to account for different timing of the onset and end of the melt season, and random errors in the GRACE observations). Similar values are found for 2003 and 2005, in which 265 Gt and 279 Gt were shed respectively. These losses are only partially compensated by mass accumulation in the preceding winter seasons. A large mass gain is observed in early 2003, almost completely offsetting the succeeding mass loss. During the 2006-2007 winter season, the Greenland ice sheet gained only $68 \mathrm{Gt}$, resulting in a net loss of $270 \mathrm{Gt}$ for the entire 2006-2007 balance year. Mass accumulation was comparable in the 2004-2005 winter season, totaling $50 \mathrm{Gt}$, which gives a net ablation of 229 Gt for the 2004-2005 year.

\section{Discussion}

[13] A strong correlation exists between summer temperature and the amount of summer mass loss. Hanna et al. [2008b] observed a significant warning of $1.7^{\circ} \mathrm{C}$ in summer temperature for 1991-2006. The summers of 2003, 2005 and 2007 were the warmest three since 1961 [Hanna et al., 2008b; Mote, 2007]. Two independent numerical models of the Greenland ice sheet [Hanna et al., 2008a], show minima in surface mass balance in 2003 and 2006 and suggest a record surface melt of the Greenland ice sheet during the summer of 2007 , preceded by very low snow accumulation in the winter months [Hanna et al., 2008a]. The GRACE observations do indeed indicate large mass losses in 2003 and 2007 and a low mass growth in 2006-2007, but the GRACE data do not confirm the 2006 minimum. However, it should be kept in mind that such models ignore ice flows when comparing the two data sets.

[14] The summer mass loss is dominated by ablation occurring along the coast (Figure 3 ). In the higher elevation zones no clear repeating pattern of summer mass loss is discernable, however, rapid ice loss appears to have occurred between April and August 2007, with a peak to peak difference of $238 \mathrm{Gt}$, followed by a period of mass accumulation. It is noteworthy that periods of mass loss above $2000 \mathrm{~m}$ are generally accompanied by accumulation below $2000 \mathrm{~m}$. Although periods of small negative trends have occurred before above $2000 \mathrm{~m}$, the duration and magnitude of the summer 2007 anomaly is unprecedented during the observation period. This validates surface melt studies based on satellite microwave data [Tedesco, 2007], observing a surface melt index (the melting area multiplied by the number of melting days) of $153 \%$ greater than the average over the last 18 years for regions above $2000 \mathrm{~m}$. Based on a longer data set, Mote [2007] reported melt frequency anomalies of up to 50 days for the southern regions above $2000 \mathrm{~m}$ in 2007 , with a melt onset occurring up to 30 days earlier than the 1973-2007 average.

[15] The GRACE spherical harmonics contain more information than previously recognized and allow regional estimation of mass changes. We find strong mass losses along the southeast coast, but also observe widespread mass loss in the Northwest. On average, Greenland contributed $0.5 \pm 0.1 \mathrm{~mm} / \mathrm{yr}$ to global mean sea level rise between 2003 and 2008. Trends are increasingly negative, partly due to the record mass loss during the summer of 2007, when mass loss occurred also at high elevations. The mass balance of Greenland is dominated by such summer events, rather than by a linear trend, and the amount of summer mass loss varies substantially during the 5 years considered. This underlines the need for extended time series and continued observations of the Earth's gravity signal as provided by GRACE.

Table 2. Overview of the Mass Changes Over the Entire Greenland Ice Sheet ${ }^{\mathrm{a}}$

\begin{tabular}{cccccc}
\hline Year & A-M-J & A-S-O & Winter Gain & Summer Loss & Net Balance \\
\hline 2003 & 525 & 260 & $235^{\mathrm{b}}$ & -265 & -30 \\
2004 & 355 & 149 & 95 & -206 & -111 \\
2005 & 199 & -80 & 50 & -279 & -229 \\
2006 & -26 & -214 & 54 & -188 & -134 \\
2007 & -146 & -484 & 68 & -338 & -270 \\
\hline
\end{tabular}

${ }^{a}$ Average values of the total mass with respect to the (2003-2008) mean are given for April-May-June (A-M-J) and August-September-October (A$\mathrm{S}-\mathrm{O})$, together with winter gain, summer loss and net balance. Units are Gt.

${ }^{\mathrm{b}}$ Calculated using February 2003 as substitute for A-S-O 2002. 
[16] Acknowledgments. We would like to thank the editor and two anonymous reviewers for their helpful comments.

\section{References}

Chen, J. L., C. R. Wilson, and B. D. Tapley (2006), Satellite gravity measurements confirm accelerated melting of Greenland ice sheet, Science, 313, 1958-1960, doi:10.1126/science.1129007.

Dietrich, R., H.-G. Maas, M. Baessler, A. Rülke, A. Richter, E. Schwalbe, and P. Westfeld (2007), Jakobshavn Isbr, West Greenland: Flow velocities and tidal interaction of the front area from 2004 field observations, J. Geophys. Res., 112, F03S21, doi:10.1029/2006JF000601.

Hanna, E., J. Cappelen, X. Fettweis, P. Huybrechts, A. Luckman, and M. Ribergaard (2008a), Hydrologic response of the Greenland ice sheet: The role of oceanographic warming, Hydrol. Processes, in press.

Hanna, E., P. Huybrechts, K. Steffen, J. Cappelen, R. Huff, C. Shuman, T. Irvine-Fynn, S. Wise, and M. Griffiths (2008b), Increased runoff from melt from the Greenland ice sheet: A response to global warming, J. Clim., 21, 331-341.

Ivins, E. R., and D. Wolf (2008), Glacial isostatic adjustment: New developments from advanced observing systems and modeling, J. Geodyn., 46, 69-77, doi:10.1016/j.jog.2008.06.002.

Luckman, A., T. Murray, R. de Lange, and E. Hanna (2006), Rapid and synchronous ice-dynamic changes in East Greenland, Geophys. Res. Lett., 33, L03503, doi:10.1029/2005GL025428.

Luthcke, S. B., H. J. Zwally, W. Abdalati, D. D. Rowlands, R. D. Ray, R. S. Nerem, F. G. Lemoine, J. J. McCarthy, and D. S. Chinn (2006), Recent Greenland ice mass loss by drainage system from satellite gravity observations, Science, 314, 1286-1289, doi:10.1126/Science.1130776.

Mote, T. L. (2007), Greenland surface melt trends 1973-2007: Evidence of a large increase in 2007, Geophys. Res. Lett., 34, L22507, doi:10.1029/ 2007GL031976.

Paulson, A., S. Zhong, and J. Wahr (2007), Inference of mantle viscosity from GRACE and relative sea level data, Geophys. J. Int., 171, 497-508, doi:10.1111/j.1365-246X.2007.03556.x.
Ramillien, G., A. Lombard, A. Cazenave, E. R. Ivins, M. Llubes, F. Remy, and R. Biancale (2006), Interannual variations of the mass balance of the Antarctica and Greenland ice sheets from GRACE, Global Planet. Change, 53, 198-208, doi:10.1016/j.gloplacha.2006.06.003.

Rignot, E., and P. Kanagaratnam (2006), Changes in the velocity structure of the Greenland ice sheet, Science, 311, 986-990, doi:10.1126/ science. 1121381 .

Stearns, L. A., and G. S. Hamilton (2007), Rapid volume loss from two East Greenland outlet glaciers quantified using repeat stereo satellite imagery, Geophys. Res. Lett., 34, L05503, doi:10.1029/2006GL028982.

Tedesco, M. (2007), A new record in 2007 for melting in Greenland, Eos Trans. $A G U, 88(39)$, doi:10.1029/2007EO390003.

Thomas, R., E. Frederick, W. Krabill, S. Manizade, and C. Martin (2006), Progressive increase in ice loss from Greenland, Geophys. Res. Lett., 33, L10503, doi:10.1029/2006GL026075.

Velicogna, I., and J. Wahr (2006), Acceleration of Greenland ice mass loss in spring 2004, Nature, 443, 329-331, doi:10.1038/nature05168.

Wahr, J., M. Molenaar, and F. Bryan (1998), Time variabilty of the earth's gravity field: Hydrological and oceanic effects and their possible detection using GRACE, J. Geophys. Res., 103, 30,305-30,229.

Wouters, B., and E. J. O. Schrama (2007), Improved accuracy of GRACE gravity solutions through empirical orthogonal function filtering of spherical harmonics, Geophys. Res. Lett., 34, L23711, doi:10.1029/ 2007GL032098.

Zwally, H. J., M. B. Giovinetto, J. Li, H. G. Cornejo, M. A. Beckley, A. C. Brenner, J. L. Saba, and D. Yi (2005), Mass changes of the Greenland and Antarctic ice sheets and shelves and contributions to sea-level rise: 1992-2002, J. Glaciol., 51(175), 509-527.

D. Chambers, Center for Space Research, University at Austin, Austin, TX 78759, USA.

E. J. O. Schrama and B. Wouters, Delft Institute of Earth Observation and Space Systems, Delft University of Technology, Kluyverweg 1, NL-2629 HS Delft, Netherlands. (bert.wouters@tudelft.nl) 